\title{
Psychrophilic methanogenic community development during long-term cultivation of anaerobic granular biofilms
}

\author{
Rory M McKeown ${ }^{1,3}$, Colm Scully ${ }^{1,3}$, Anne-Marie Enright ${ }^{1}$, Fabio A Chinalia ${ }^{1,4}$, \\ Changsoo Lee ${ }^{1}$, Thérèse Mahony ${ }^{1}$, Gavin Collins ${ }^{2}$ and Vincent O'Flaherty ${ }^{1}$ \\ ${ }^{1}$ Microbial Ecology Laboratory, National University of Ireland, Galway, Ireland and ${ }^{2}$ Microbial Ecophysiology \\ Research Group, Department of Microbiology and Environmental Change Institute, National University \\ of Ireland, Galway, Ireland
}

\begin{abstract}
Granular biomass was temporally sampled from a cold $\left(4-15^{\circ} \mathrm{C}\right)$ anaerobic bioreactor, which was inoculated with mesophilic biomass and used to treat industrial wastewater in a long-term (3.4 year) study. Data from 16S rRNA gene clone libraries, quantitative PCR and terminal restriction fragment length polymorphism analyses indicated that microbial community structure was dynamic, with shifts in the archaeal and bacterial communities' structures observed following start-up and during temperature decreases from 15 to $9.5^{\circ} \mathrm{C}$ (phase 1). Specifically, the relative abundance of architecturally important Methanosaeta-like (acetoclastic) methanogens decreased, which was concomitant with granule disintegration and the development of a putatively psychrophilic hydrogenotrophic methanogenic community. Genetic fingerprinting suggested the development of a psychroactive methanogenic community between 4 and $10^{\circ} \mathrm{C}$ (phase 2), which was dominated by acetogenic bacteria and Methanocorpusculum-like (hydrogenotrophic) methanogens. High levels of Methanosaeta-like acetoclastic methanogens and granular biofilm integrity were maintained during phase 2. Overall, decreasing temperature resulted in distinctly altered microbial community structure during phase 1 , and the development of a less dynamic psychroactive methanogenic consortium during phase 2. Moreover, psychrophilic $\mathrm{H}_{2}$-oxidizing methanogens emerged as important members of the psychroactive consortia after $>1200$ days of low-temperature cultivation. The data suggest that prolonged psychrophilic cultivation of mesophilic biomass can establish a well-functioning psychroactive methanogenic consortium, thus highlighting the potential of low-temperature anaerobic digestion technology.
\end{abstract}

The ISME Journal (2009) 3, 1231-1242; doi:10.1038/ismej.2009.67; published online 25 June 2009

Subject Category: microbial population and community ecology

Keywords: 16S rRNA gene fingerprinting; community development; phylogenetic diversity; low-temperature anaerobic digestion; methanogenesis; psychroactivity

\section{Introduction}

Three quarters of the Earth's biosphere is permanently exposed to low temperatures (Metje and Frenzel, 2007). Psychrotrophic and psychrophilic Archaea contribute significantly to the biomass in the predominantly cold biosphere (for example, c. $10^{28}$ cells in the world's oceans) and typically, these habitats are characterized by hypoxic/anoxic

Correspondence: V O’Flaherty, Microbial Ecology Laboratory, National University of Ireland, Galway (NUI, Galway), University Road, Galway, Ireland.

E-mail: vincent.oflaherty@nuigalway.ie

${ }^{3}$ These authors contributed equally to this work.

${ }^{4}$ Current address: Centre for Resource Management and Efficiency, School of Applied Science, Cranfield University, College Road, Cranfield, Bedfordshire, MK43 0AL, UK

Received 4 February 2009; revised 27 April 2009; accepted 1 May 2009; published online 25 June 2009 conditions and are low in inorganic terminal electron acceptors (Horn et al., 2003). Under such conditions, organic matter is principally biotransformed through methanogenesis (Conrad et al., 1989). During anaerobic digestion (AD), organic matter is sequentially degraded by complex microbial consortia to simple precursor compounds, such as acetate, $\mathrm{H}_{2} / \mathrm{CO}_{2}$, formate and methanol, from which methanogenic Archaea produce methane and carbon dioxide (biogas). Temperature influences the rate and path of carbon flow during methanogenesis by affecting the activity of particular microbial groups and the structure of the consortia (Glissmann et al., 2004). Normally, two-thirds of methane is produced through acetate (Conrad, 1999). In lowtemperature natural environments, acetoclastic methanogenesis is widely reported as the dominant methanogenic pathway (Schulz et al., 1997; Fey et al., 2004). Increased acetate production through 
Table 1 Operational and performance characteristics during phase 1 and 2 of operation (summarized from McKeown et al., 2009)

\begin{tabular}{|c|c|c|c|c|c|c|c|c|c|c|}
\hline \multirow[t]{2}{*}{ Phase period } & \multicolumn{6}{|c|}{1} & \multicolumn{4}{|c|}{2} \\
\hline & $I$ & II & III & $I V$ & V & $V I$ & VII & VIII & $I X$ & $X$ \\
\hline Days & $0-434$ & $435-516$ & $517-557$ & $558-583$ & $584-630$ & $631-673$ & $674-830$ & 831-1057 & $1058-1161$ & $1162-1243$ \\
\hline $\mathrm{T}^{\mathrm{a}}$ & 15 & 13.5 & 12.5 & 11.5 & 10.5 & 9.5 & $9-8.5$ & $10-7$ & $6-5$ & 4 \\
\hline $\mathrm{HRT}^{\mathrm{b}}$ & $24 / 12$ & 12 & 12 & 12 & 12 & 12 & 24 & 24 & 24 & 24 \\
\hline $\mathrm{OLR}^{\mathrm{c}}$ & $5 / 10$ & 10 & 10 & 10 & 10 & 10 & 5 & 5 & 5 & $5 / 3.75$ \\
\hline CODRE $^{\mathrm{d}}$ & $92 \pm 7$ & $91 \pm 7$ & $93 \pm 4$ & $91 \pm 2$ & $81 \pm 11$ & $85 \pm 11$ & $74 \pm 13$ & $86 \pm 7$ & $87 \pm 8$ & $82 \pm 9$ \\
\hline
\end{tabular}

aTemperature $\left({ }^{\circ} \mathrm{C}\right)$.

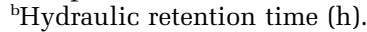

'Organic loading rate $\left(\mathrm{kg}\right.$ of $\left.\mathrm{COD} \mathrm{m}{ }^{-3} \mathrm{~d}^{-1}\right)$.

${ }^{\mathrm{d} C h e m i c a l}$ oxygen demand removal efficiency (\%), where values are the period mean ( \pm s.d.).

enhanced homoacetogenic activity may account for this phenomenon in low-temperature environments (Schulz and Conrad, 1996). However, hydrogenotrophic methanogenesis has also been shown to play an important role in cold terrestrial habitats (Horn et al., 2003; Kotsyurbenko et al., 2007). It is proposed that the predicted increase in global temperatures will result in substantially increased methane emissions from cold biomes (Galand et al., 2003). As methane is a potent greenhouse gas, its increased emission will likely further accelerate climate change (Metje and Frenzel, 2007).

In addition to this, $\mathrm{AD}$ has long been applied for the reclamation of industrial and domestic wastewater. Low-temperature AD (LTAD) has emerged as an economically attractive waste treatment strategy, which confers considerable advantages over conventional mesophilic $\left(>20^{\circ} \mathrm{C}\right)$ and thermophilic $\left(>45^{\circ} \mathrm{C}\right)$ treatments, primarily due to increased net energy yields (Lettinga et al., 2001). This technology has been successfully applied at laboratory-scale for the treatment of a broad range of wastewaters (for example, Rebac et al., 1999; Enright et al., 2005; Collins et al., 2006; Syutsubo et al., 2008; Bergamo et al., 2009). Improved bioreactor designs now enable high rates of conversion under low-temperature conditions through a combination of (i) high mixing intensities (that is, facilitates high rates of mass transference) and (ii) enhanced retention of psychroactive biomass. Indeed, LTAD is poised to replace aerobic microbiological treatments as the core process of waste-to-energy technologies for enhanced sustainability in the coming decade.

Yet, comparatively little is known about the genetics and physiology of the microorganisms inhabiting cold environments, or of the molecular mechanisms that facilitate low-temperature survival. Indeed full-scale LTAD application is hindered by a deficit of fundamental information on the microbial interactions underpinning the process, which may lead to unstable and sub-optimal performance. To comprehend and exploit microbial communities from low-temperature environments, information on the pathways of lowtemperature biodegradation and the in situ ecophysiology of psychroactive organisms is required.
Recently, we reported on the performance of a low-temperature $\left(4-15{ }^{\circ} \mathrm{C}\right)$ anaerobic bioreactor during a long-term trial (3.4 years; McKeown et al., 2009). In this study, $16 \mathrm{~S}$ rRNA gene-based techniques and physiological assays were applied to biomass samples to monitor the microbial population dynamics and the emergence of psychrophilic methanogens during the trial.

\section{Materials and methods}

\section{Source of biomass}

Temporal samples of biomass were obtained from an expanded granular sludge bed anaerobic filter hybrid bioreactor, which was originally seeded with a mesophilic inoculum, that was used to treat a moderate-strength volatile fatty acid (VFA)-based wastewater between 4 and $15^{\circ} \mathrm{C}$ (McKeown et al., 2009). The trial was organized into two experimental phases, phase 1 (period (P) I-VI) and phase 2 (PVII-X), which were each characterized by changes applied either to the operational temperature or the hydraulic conditions, and are presented in detail in Table 1.

\section{Physiological assays}

Batch specific methanogenic activity (SMA) assays were performed using the seed inoculum and reactor biomass samples from day 673 and day 1243 according to the protocols developed by Colleran et al. (1992) and Coates et al. (1996), and as described in detail in McKeown et al. (2009). At 15 months after the conclusion of the trial, the hydrogenotrophic methanogenic activity of the reactor biomass-which had been stored at $4{ }^{\circ} \mathrm{C}$ without receiving any additional substratewas determined.

\section{Extraction and amplification of $16 S$ rRNA genes}

Total community nucleic acids were extracted from biomass sampled at: day 0 (mesophilic inoculum), days $94,136,268,275,301$ and 428 (all $15^{\circ} \mathrm{C}$ ), days $506\left(13.5^{\circ} \mathrm{C}\right), 673\left(9.5^{\circ} \mathrm{C}\right), 820\left(8.5^{\circ} \mathrm{C}\right), 849\left(10^{\circ} \mathrm{C}\right)$, 
$918\left(9.5^{\circ} \mathrm{C}\right), 960\left(9^{\circ} \mathrm{C}\right), 969\left(8.5^{\circ} \mathrm{C}\right), 988\left(8^{\circ} \mathrm{C}\right), 1019$ $\left(7.5^{\circ} \mathrm{C}\right), 1059\left(7^{\circ} \mathrm{C}\right)$, days 1093,1111 and 1135 (all $\left.6{ }^{\circ} \mathrm{C}\right)$, day $1162\left(5^{\circ} \mathrm{C}\right)$, day $1194\left(4^{\circ} \mathrm{C}\right)$ and day 1228 $\left(4^{\circ} \mathrm{C}\right.$; granular sludge bed and fixed-film anaerobic filter biomass). From day 0-706, total genomic DNA was extracted from biomass samples as described by Collins et al. (2003); from day 707-1243, DNA was extracted according to the protocol of Griffiths et al. (2000).

\section{Clone library analysis of $16 S$ rRNA genes}

Clone libraries were constructed from samples of the seed inoculum (Bacteria and Archaea) and biomass sampled on day 673 (Bacteria only) and day 1228 (Bacteria and Archaea). Bacterial 16S rRNA genes were amplified with forward primer 27F (5'-AGAGT TTGATCCTGGCTCAG-3'; DeLong, 1992) and reverse primer 1392R (5'-ACGGGCGGTGTGTRC-3'; Lane et al., 1985). Archaeal 16S rRNA genes were amplified with forward primer 21F (5'-TTCCGGTTG ATCCYGCCGGA-3'; Stackebrandt and Goodfellow, 1991) and reverse primer 958R (5'-YCCGGCGTTGA MTCCAATT-3'; DeLong, 1992). PCR mixtures and reaction conditions are described by Enright et al. (2007). Cloning (TOPO TA; Invitrogen, Carlsbad, CA, USA), amplified ribosomal DNA restriction analysis (ARDRA), plasmid sequencing and phylogenetic analyses were carried out as outlined by Collins et al. (2003).

\section{Accession numbers}

The partial 16S rRNA gene sequences determined in this study were assigned the following accession numbers: Bacteria-DQ386699-DQ386704 (inoculum); EU722369-EU722392 (day 673); EU722352EU722368 (day 1228); Archaea-DQ679927-DQ679933 (inoculum); FJ347527-FJ347532 (day 1228).

\section{TRFLP analysis}

Terminal restriction fragment length polymorphism (TRFLP) analysis of PCR-amplified 16S rRNA genes was carried out as above, except that reverse primers (1392R and 958R) were $5^{\prime}$-carboxyflourescein (FAM) labelled and forward primers $(27 \mathrm{~F}$ and $21 \mathrm{~F})$ were 5'-hexachloroflourescein (HEX) labelled. Enzymatic restriction with $\mathrm{HhaI}$ was carried out as per the manufacturer's instruction (Promega, Woods Hole, WI, USA). Terminal restriction fragments (TRFs) were sized using an ABI 310 capillary gene sequencer (Gene Analysis Service, Berlin, Germany).

Terminal restriction fragment length polymorphism data analysis was conducted either qualitatively by creating binary matrices whereby the presence (' 1 ') or absence ('0') of individual TRFs was scored, or semi-quantitatively by calculating the relative abundance of TRFs normalized by the total area of the respective TRF patterns. Additional information pertaining to the multivariate statistical analysis of
TRFLP matrices by non-metric multidimensional scaling ordination and cluster analysis is provided in Supplementary Materials.

\section{Quantitative PCR assays}

Methanomicrobiales and Methanosaetaceae populations were quantified by real-time PCR (qPCR) using the DNA samples of days 673, 820, 1059 and 1228. qPCR was carried out using a LC 480 (Roche, Mannheim, Germany) with two primer/probe sets, MMB- and Mst-sets, specific for Methanomicrobiales and Methanosaetaceae, respectively (Yu et al., 2005). Each reaction mixture was prepared using the LC 480 Probes Master kit following the manufacturer's instructions (Roche). Details pertaining to thermal cycling information and construction of quantification standard curves are provided in Supplementary Materials. The $16 \mathrm{~S}$ rRNA gene population ratio of Methanomicrobiales to Methanosaetaceae was directly calculated by dividing the quantified result for the MMB-set by that for the Mst-set.

\section{Results}

Bioprocess-related data

After a rapid start-up phase (c. 10 days), efficient reactor performance was recorded during PI-IV (11.5-15 ${ }^{\circ} \mathrm{C}$; Table 1). A decline in performance efficiency concomitant with significant granule disintegration was observed during PVI (9.5$\left.10.5^{\circ} \mathrm{C}\right)$. Despite relatively unsteady performance during operation between PV-PVII $\left(8.5-10.5^{\circ} \mathrm{C}\right)$, the system operated generally $>70 \%$ chemical oxygen demand removal efficiency (CODRE; Table 1). During PVIII-IX $\left(5-10^{\circ} \mathrm{C}\right)$, remarkably stable and efficient performance was observed (CODRE, > $85 \%$; Table 1). The reduction in operating temperature to $4{ }^{\circ} \mathrm{C}$ effected a decline in treatment efficiency, which recovered to $>80 \%$ CODRE once the applied organic load was reduced on day 1194 (PX; Table 1). A complete description of the treatment trial is provided elsewhere (McKeown et al., 2009).

\section{Physiological characterization}

The mesophilic nature of the seed inoculum was demonstrated (Table 2). By day 673, the enrichment of propionotrophic and hydrogenotrophic psychroactivity was in evidence. Furthermore, methanogenic activity against $\mathrm{H}_{2} / \mathrm{CO}_{2}$ was significantly higher at $15^{\circ} \mathrm{C}$ than at $37^{\circ} \mathrm{C}$, suggesting the putative emergence of psychrophilic hydrogenotrophic activity (Table 2). Depressed acetoclastic activity was apparent by day 673 (Table 2). At the conclusion of the trial, SMA data indicated higher hydrogen- and propionate-utilizing activity at $15^{\circ} \mathrm{C}$ than at $37^{\circ} \mathrm{C}$ (Table 2). Improved methanogenic activity against acetate was apparent, but it was higher at $37^{\circ} \mathrm{C}$ than at $15^{\circ} \mathrm{C}$ (Table 2). The hydrogenotrophic methanogenic activity of the biomass 15 months 
Table 2 Physiological characterization of temporal biomass; specific methanogenic activity $\left(\mathrm{ml} \mathrm{CH}_{4} \mathrm{~g}(\mathrm{VSS})^{-1} \mathrm{~d}^{-1}\right)$; adapted from McKeown et al. (2009)

\begin{tabular}{lcccc}
\hline Biomass & ${ }^{\circ} \mathrm{C}$ & Seed inoculum & Day 673 & Day 1243 \\
\hline Propionate & 37 & $23 \pm 2$ & $57 \pm 2$ & $51 \pm 4$ \\
& 15 & $15 \pm 1$ & $30 \pm 1$ & $80 \pm 5^{\mathrm{a}}$ \\
Acetate & 37 & $78 \pm 1$ & $69 \pm 1$ & $370 \pm 29$ \\
& 15 & $31 \pm 2$ & $17 \pm 1$ & $83 \pm 7$ \\
$\mathrm{H}_{2} / \mathrm{CO}_{2}$ & 37 & $51 \pm 2$ & $52 \pm 2$ & $297 \pm 12$ \\
& 15 & $23 \pm 2$ & $76 \pm 1$ & $400 \pm 41$ \\
\hline
\end{tabular}

All values are the mean of triplicates \pm s.e. $(n=3)$.

${ }^{a}$ Values are the mean of duplicates \pm s.e. $(n=2)$.

after the conclusion of the bioreactor trial was $(\mathrm{ml}$ $\mathrm{CH}_{4} \mathrm{~g}$ (volatile suspended solids [VSS]) ${ }^{-1} \mathrm{~d}^{-1}$ ) 99 at $37^{\circ} \mathrm{C}, 479$ at $15^{\circ} \mathrm{C}, 27$ at $10^{\circ} \mathrm{C}$ and 10 at $4^{\circ} \mathrm{C}$.

\section{Clone library analysis}

Phylogenetic analysis indicated that bacterial clones closely related to Bacteroidetes $(50 \%)$ and Proteobacteria $(12 \%)$ were predominant in the inoculum sludge (Figures 1a, 2a). By day 673, however, a diverse community of Firmicutes-like clones dominated the library (Figures 1a, 2b). Bacteroidetes (55\%) and Firmicutes $(27 \%)$ were the predominant community members on day 1228 (Figures 1a, 2c).

ARDRA identified 13 different operational taxonomic units (OTUs) from archaeal clone libraries; seven OTUs from the seed sludge and six OTUs from reactor biomass sampled on day 1228 (Figures 1b, 2d). Methanosaeta- and Methanomethylovoranslike clones comprised $77 \%$ and $7 \%$ of the archaeal library, respectively (Figure 2d). Crenarchaeota were represented by two OTUs (accession numbers, DQ679927 and DQ679928), which accounted for $16 \%$ of all archaeal clones, were closely related to environmental crenarchaeal clones previously obtained from non-thermophilic environments (Figures 1b, 2d). By day 1228, a shift in the archaeal community structure was evident with the disappearance of non-methanogenic organisms (Figures 1b, 2e). Methanosaeta-like clones were still a major constituent of the archaeal community at the conclusion of the trial (c. $46 \%$ of total archaeal community), but their relative abundance had diminished from the seed inoculum (Figure 2e). Conversely, hydrogenotrophic Methanocorpusculum-like clones were dominant at day 1228 (54\% of total archaeal community; Figure 2e).

\section{Microbial community dynamics}

Non-metric multidimensional scaling ordinations of TRFLP matrices derived from the HhaI-forward primer profile showed a shift in the structure of the bacterial and archaeal communities after reactor start-up (Figure 3). This observation was recurrent in the non-metric multidimensional scaling ordinations and cluster analysis of the bacterial and archaeal HhaI-reverse profiles (Supplementary Figures SM1, SM2 and SM3). Overall, the microbial community appeared more closely grouped, and thus less dynamic during phase 2 (from PVIII; Figure 3; Supplementary Figures SM1, SM2 and SM3). A distinct, albeit transient, shift in the bacterial and archaeal population structure was evident on day 673, coincident with a period of poor operational stability (Figure 3). Cluster analysis dendograms illustrated three distinct stages of archaeal community succession: (i) the mesophilic seed $\left(37^{\circ} \mathrm{C}\right)$, (ii) a dynamic community during operation at $15^{\circ} \mathrm{C}$ and (iii) a relatively less dynamic community during operation at $<15{ }^{\circ} \mathrm{C}$ (Supplementary Figure SM3).

In silico restriction analysis of bacterial clonal sequences resulted in low phylogenetic resolution. Accordingly, this monitoring technique was not used to resolve the fate of bacterial clonal sequences throughout the trial. In silico restriction analysis of archaeal clonal sequences suggested that TRFs detected during the trial were characteristic of certain groups, thus enabling their temporal fate to be monitored (Figure 4a, b). A complete description of the TRF fragment length resolved from in silico restriction analysis of archaeal clones is presented in Supplementary Materials (Supplementary Table SM1). TRF patterns generated using the HhaI-forward primer combination indicated that Methanosaeta-like ribotypes (193 bp) were dominant members of the archaeal community (Figure 4b). The Methanosaetalike ribotype was not detected on days 506 and 673after the temperature reduction to $13.5^{\circ} \mathrm{C}$ on day 435-and was replaced by a cluster of unidentified TRFs (Figure 4b). A TRF of $341 \mathrm{bp}$ was transiently detected between days 820 and 969 (Figure 4b) following a period of reactor instability, but was not detected after day 1111 when efficient performance was resumed (Figure 4b). This TRF was not retrieved from clonal sequences, but was identified from an in-house in silico restriction database as a Methanosarcina-like ribotype. The Methanosaeta-like TRF signal re-emerged from day 820 and was detectable at high relative abundance for the remainder of phase 2 (Figure 4b). Methanobacterium-like TRFs (331 bp; identified from an in-house database) were also dominant throughout phase 2 (Figure 4 b). The relative abundance of this TRF increased from day 918 to $1111\left(6-10^{\circ} \mathrm{C}\right)$, but diminished from day $1135\left(<6^{\circ} \mathrm{C}\right.$; Figure 4b). A Methanocorpusculum-like ribotype (121 bp) was increasingly dominant at operational temperatures $<10^{\circ} \mathrm{C}$ (Figure 4a).

\section{qPCR analysis}

Quantitative real-time PCR assays showed that the ratio of the order Methanomicrobiales to the family Methanosaetaceae during phase 2 was 0.07 , 
$0.02,1.09$ and 2.23 on days $673,820,1059$ and 1228 , respectively. These data support the trend identified by SMA assays (Table 2) and was in agreement with semi-quantitative data from clonal library (Figure 2b) and TRFLP analyses (Figure 4a), which suggested the emergence of hydrogenotrophic groups as dominant members of the archaeal community during the latter half of the trial.

\section{Discussion}

The feasibility of long-term psychrophilic anaerobic bioreactor operation has been demonstrated at $4{ }^{\circ} \mathrm{C}$ (McKeown et al., 2009). The community fingerprinting data presented in this study indicate that a wellbalanced psychroactive methanogenic consortium developed during this long-term LTAD trial. Genetic and physiological analyses indicated that

a

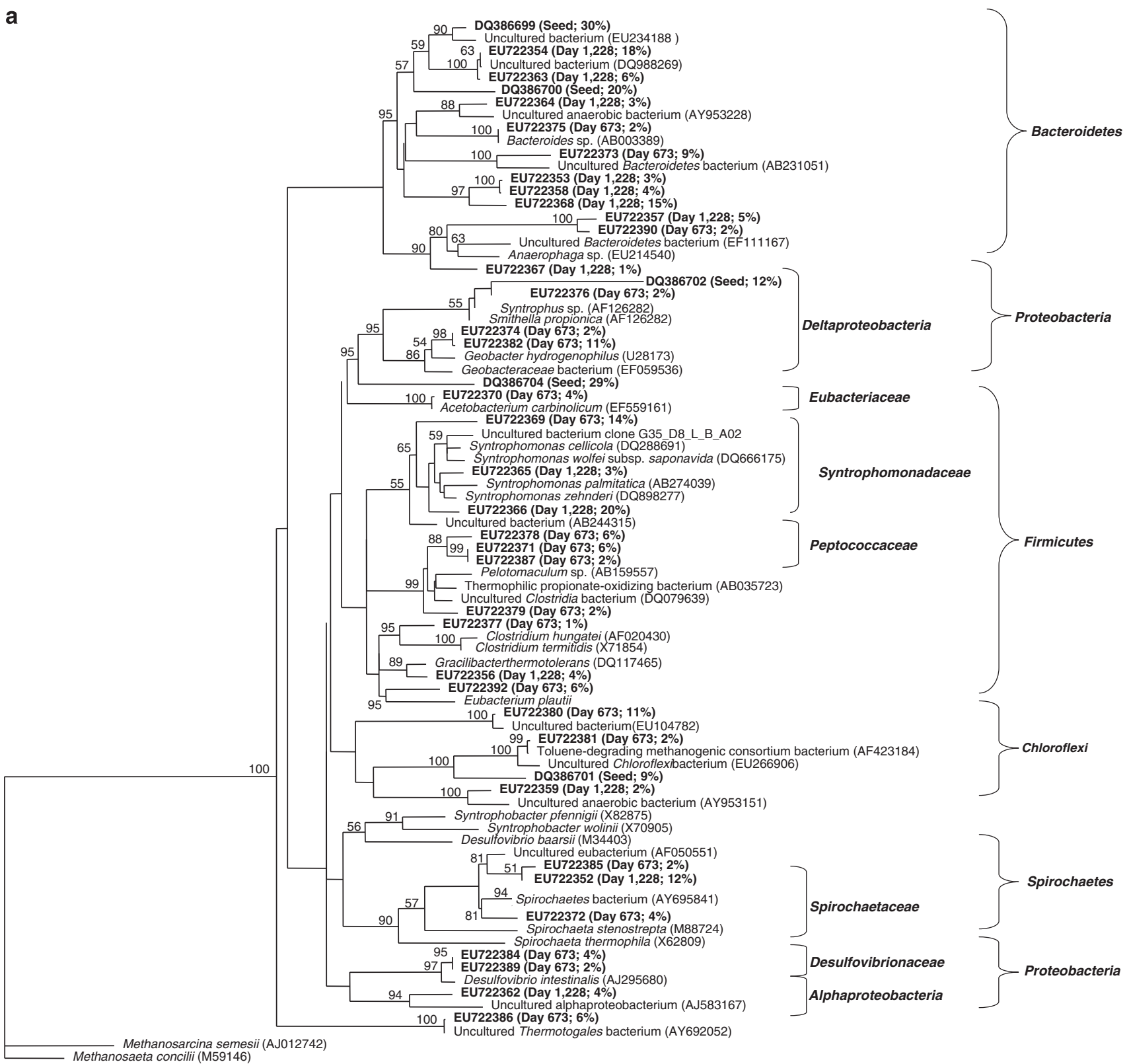

_ 0.01 substitutions/site

Figure 1 Phylogeny of (a) bacterial sequences obtained from seed sludge (accession numbers DQ386699-DQ386704) and temporal reactor biomass on day 673 (accession numbers EU722369-EU722392) and day 1228 (accession numbers EU722352-EU722368), and (b) archaeal sequences obtained from seed sludge (accession numbers DQ679927-DQ679933) and reactor biomass (day 1228; accession numbers FJ347527-FJ347532). Phylogeny was calculated using the Kimura-2 algorithm and the neighbour-joining method (Saitou and Nei, 1987). Bootstrap replicates supporting the branching order are shown at relevant nodes (total 100 replicate samplings). Biomass source and coverage of clonal sequences (\%) are given in parentheses. 


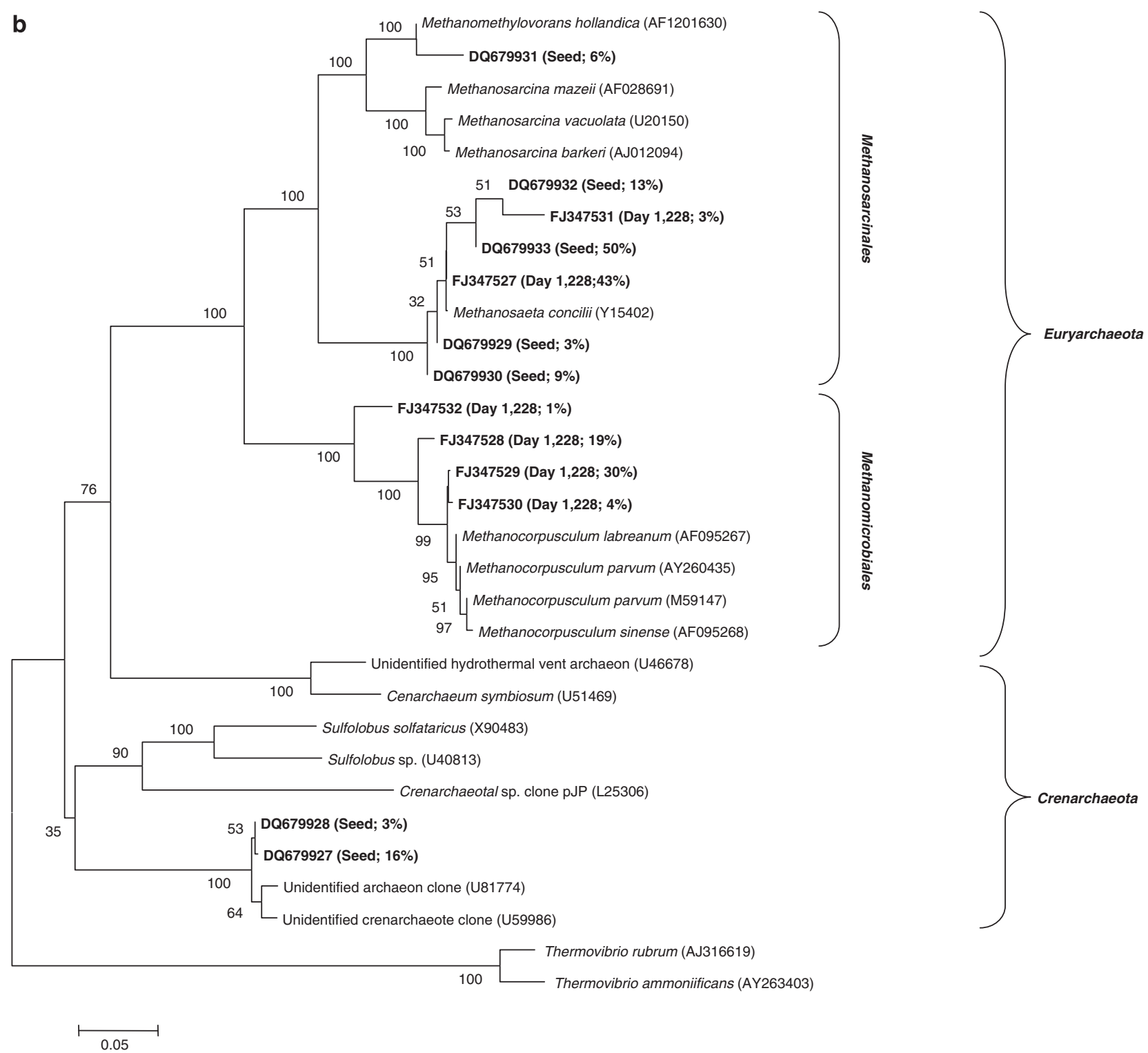

Figure 1 Continued.

temperature affected the community structure of the mesophilic seed biomass during cultivation at $<15^{\circ} \mathrm{C}$, and that distinct stages of community development occurred over the trial, ultimately resulting in reduced dynamism and high methanogenic activity under low-temperature conditions.

\section{Bacterial community structure and population} dynamics Spirochaetes emerged by day 673 and were also detectable at the conclusion of the trial. This group are typically found in organic-rich oxygen-poor environments, where they may show both fermentative and acetogenic metabolism; they may be significant bacterial community members within mesophilic granular biofilms, representing up to $25 \%$ of total bacterial community (Hernon et al., 2006). However, this group has not been reported to play a significant role in low-temperature consortia. Although they seem to be numerically important in our psychroactive consortium, their function remains unclear.

Propionate is a key intermediate in the biotransformation of organic material within anaerobic digesters (DeBok et al., 2004). Owing to the typically low prevailing sulphate concentrations in anaerobic digesters, propionate is principally degraded by syntrophs coupled with $\mathrm{H}_{2}$-consuming methanogenesis (Ariesyady et al., 2007). A putatively psychrophilic propionate-utilizing population was evident in the activity profiles of the reactor biomass by the conclusion of the trial (Table 2). This observation is important for the application of LTAD as propionate oxidation has been identified as the rate-limiting step under cold operational conditions (Rebac et al., 1999). Clone library analysis showed the high relative abundance of clonal sequences closely 

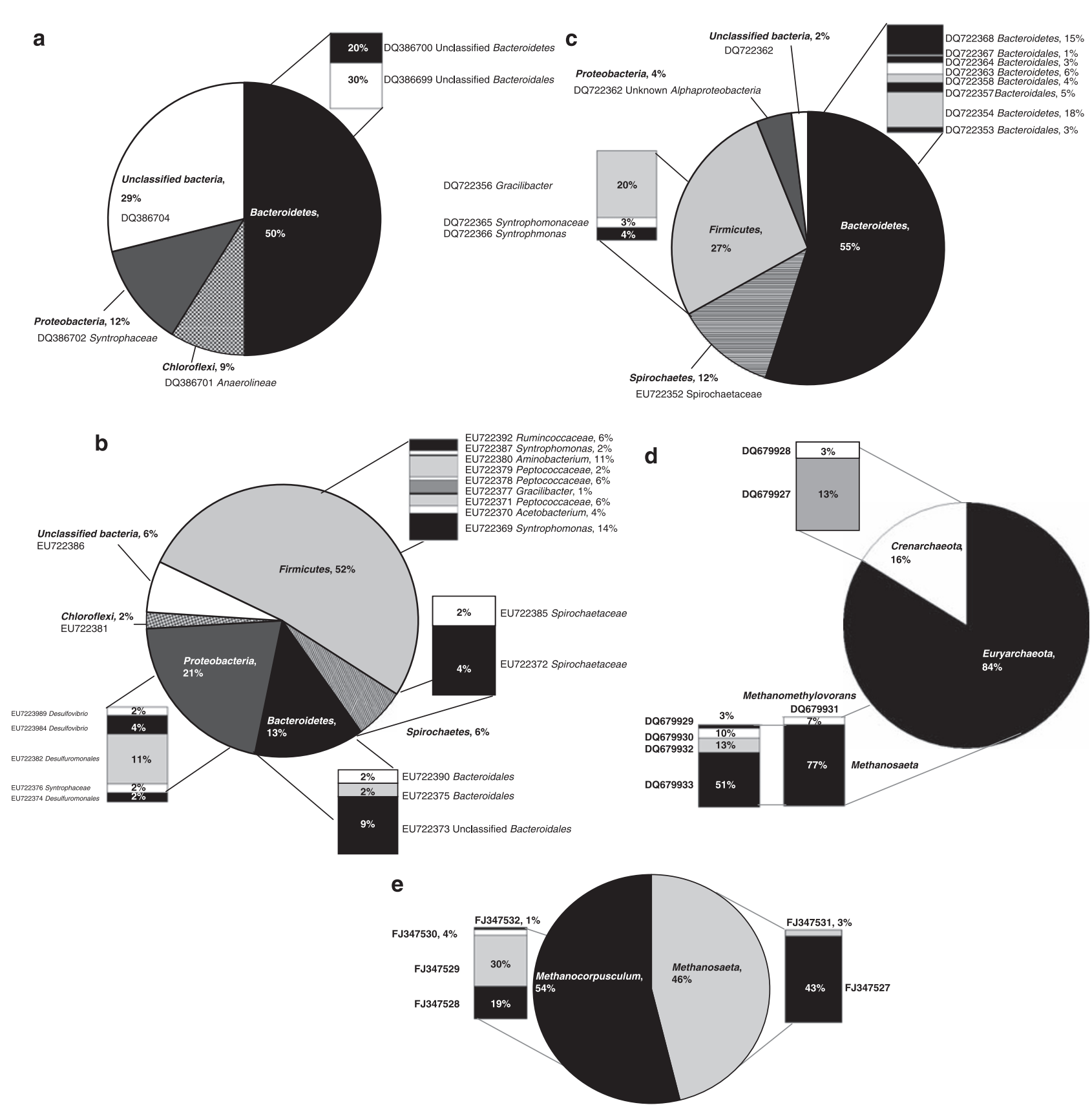

Figure 2 Comparative distribution of bacterial groups detected by clone library analysis carried out on (a) seed inoculum and reactor biomass on (b) day 673 and (c) day 1228, and archaeal groups detected by clone library analysis on (d) seed inoculum and (e) reactor biomass (day 1228).

related to organisms with potential for propionate oxidation, namely, Smithella, Syntrophus, Syntrophomonas, Pelotomaculum and Desulfovibrio spp. (Figure 1a). It is likely that these groups were responsible for the apparent psychrophilic propionotrophic activity shown by batch activity assays (day 1243; Table 2).

The Chloroflexi are reported to be important community members within mesophilic and thermophilic wastewater treatment systems, where they may represent up to $20 \%$ of the total microbiota (Chouari et al., 2005; Levén et al., 2007). Yet, few reports exist that describe their importance within cold environments. The reduced relative abundance of Chloroflexi by day 673, and the inability to detect them by day 1228, suggests that this group were functionally redundant within the low-temperature consortium, or lacked the ability to adapt to psychrophilic conditions (Figure 2).

\section{Archaeal community structure and population} dynamics

Methanogenic Archaea were relatively more abundant in the seed biomass than non-methanogenic archaeal groups (Figure 2d). The prevalence of 

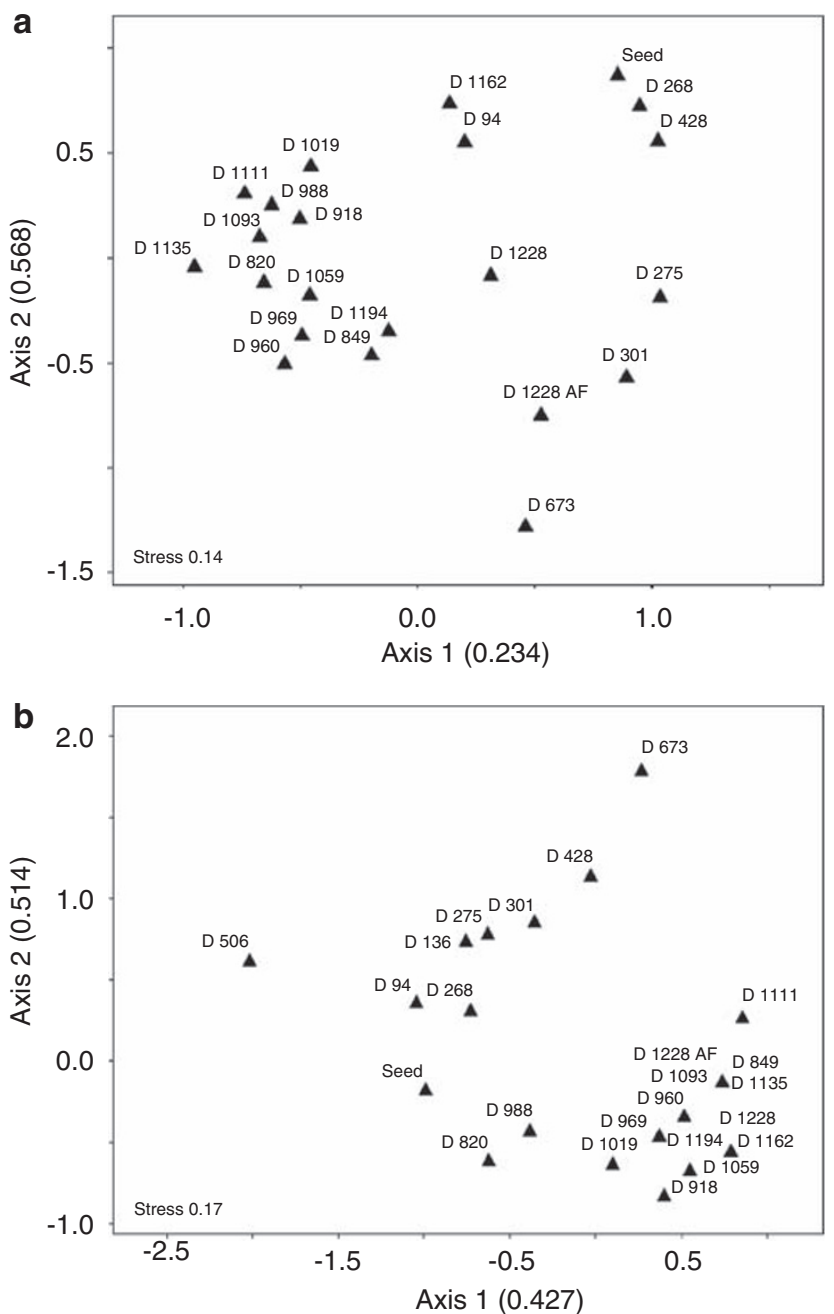

Figure 3 Non-metric multidimensional scaling plot for the terminal restriction fragment length polymorphism spectra derived from the (a) bacterial and (b) archaeal HhaI-forward primer profiles. Percentage of variance for each axis is given in parentheses.

Crenarchaeota-like clones (Group 1.3) has been reported in both mesophilic (Chouari et al., 2005; Levén et al., 2007) and psychrophilically cultivated anaerobic granular biomass, where they may represent a significant proportion of the total archaeal microbiota (Collins et al., 2005; McHugh et al., 2005). No Crenarchaeota-like ribotypes were detected at the conclusion of the trial (Figure 2e), which is in accordance with the findings of McHugh et al. (2004) and Enright et al. (2007), who reported the disappearance of Crenarchaeota-like clones during low-temperature wastewater treatment trials. Contrary to these data, studies on Arctic peat slurries have demonstrated that non-methanogenic Archaea (including group 1.3b Crenarchaeota) were increasingly important at low temperatures (Нøj et al., 2008). The role of non-thermophilic Crenarchaeota in natural and engineered low-temperature environments remains elusive.

Methanosaeta-like organisms were dominant throughout the trial (Figures 2d, e) and are believed to be competitive in established methanogenic communities (Jetten et al., 1990; McHugh et al., 2003). The transient disappearance of the Methanosaeta-like TRF signal was observed on days 506 and 673 (PII-VI; 9.5-13.5 ${ }^{\circ} \mathrm{C}$; Figure 4b). Furthermore, batch physiological assays indicated no significant development of acetoclastic methanogenic activity up to day 673 (Table 2). We posit that the temporal loss of these architecturally important ribotypes lead to the observed granule disintegration during PVI, as the filamentous Methanosaeta are believed to play an important role in the formation and maintenance of granular sludge in anaerobic bioreactors (McHugh et al., 2005). No significant disintegration of the granular sludge occurred during phase 2 . This observation, coupled with continued detection of Methanosaeta-like TRFs during phase 2, showed that architecturally important ribotypes may be maintained within granular biofilms during long-term operation at temperature $<10^{\circ} \mathrm{C}$.

A Methanosarcina-like TRF transiently appeared between days 820 and 969 (Figure 4b), corresponding to a period of reactor instability immediately after the temperature shock and subsequent to the temporal loss of the Methanosaeta-like signal. Methanosarcina have been observed in systems experiencing poor performance and may be indicative of operational instability and acetate accumulation (McMahon et al., 2004). Methanosaeta have been shown to out-compete Methanosarcina under conditions of (i) low residual acetate concentration (Griffin et al., 1998) and (ii) low temperature (Chin et al., 1999). It is likely that, under steady operational conditions, the low prevailing residual acetate concentrations (typically $<30 \mathrm{mg} \mathrm{l}^{-1}$; VFA data not shown), coupled with the reduced operational temperature, contributed to the suppression of Methanosarcina by Methanosaeta groups for the majority of the trial. However, VFA analysis carried out during days 805-835 showed that residual acetate concentrations within the system peaked at c. $156 \mathrm{mg} \mathrm{l}^{-1}$ (VFA data not shown), which is above the threshold values required to support Methanosarcina (Jetten et al., 1990). Accordingly, we submit that the reduced operational performance and subsequent acetate accumulation observed between days 820 and 969 enabled Methanosarcina to temporally accumulate within the biofilm, thus allowing their transient detection by TRFLP analysis. The subsequent resumption of stable and efficient operation likely led to the re-emergence of Methanosaeta as the dominant acetoclastic population.

\section{Changes in trophic structure and redistribution} of carbon flow

Studies have documented that, under low-temperature conditions, acetate represents the main precursor of methanogenesis in both natural (Schulz 
a

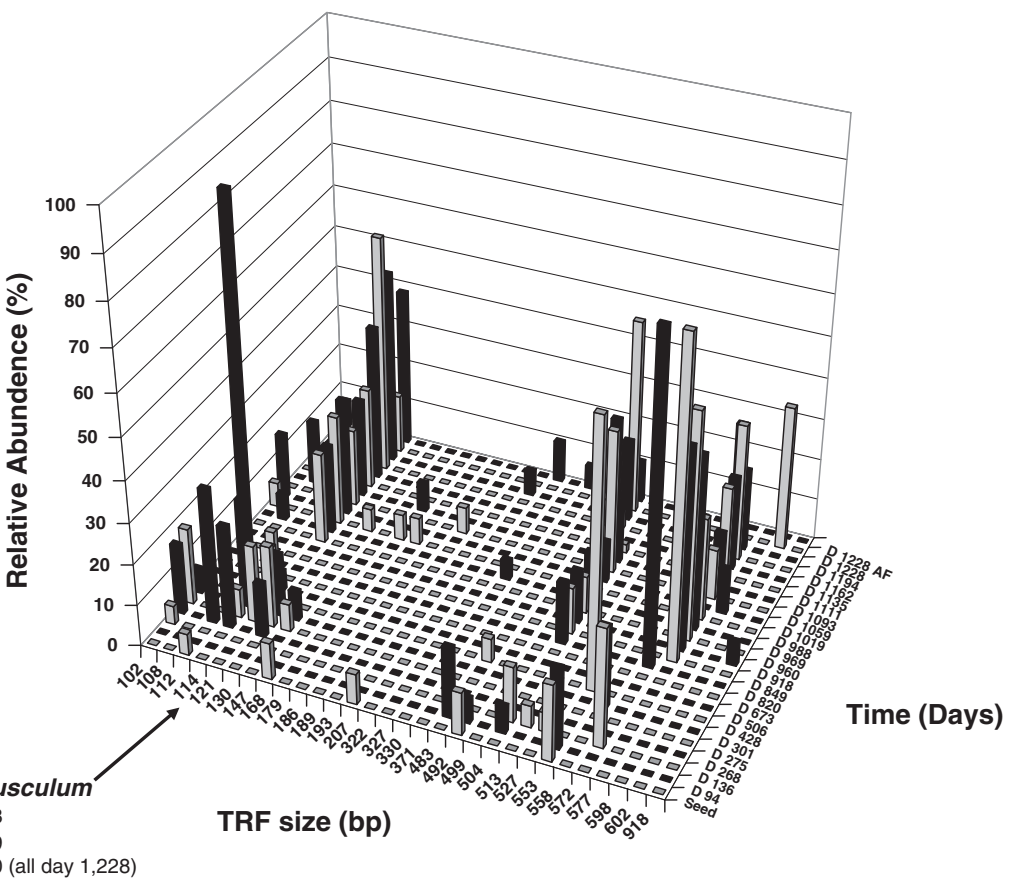

Clones: FJ347528 FJ347529

FJ347530 (all day 1,228

b

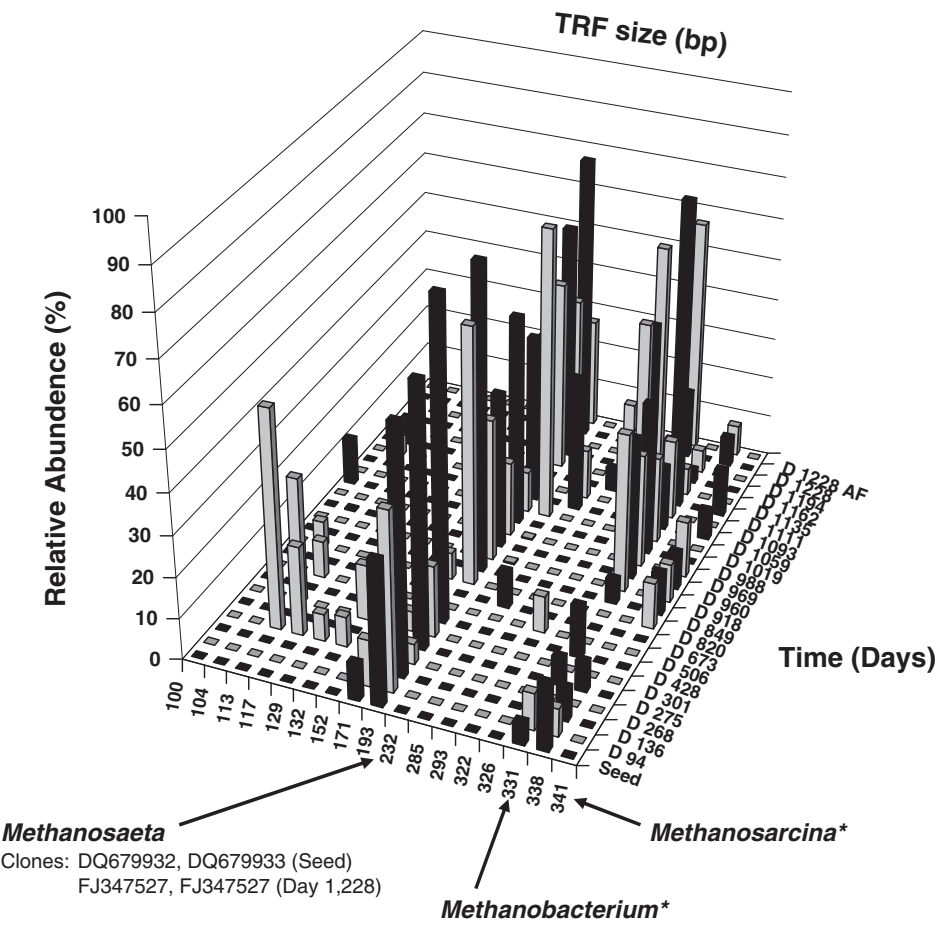

Figure 4 Temporal relative abundance of Archaea calculated from the (a) HhaI-reverse and (b) HhaI-forward primer profiles. * denotes identification from in-house in silico restriction database. TRF, terminal restriction fragments.

et al., 1997; Fey et al., 2004; Glissmann et al., 2004) and engineered systems (McHugh et al., 2003; Akila and Chandra, 2007). Such a shift is likely as a result of enhanced homoacetogenic activity (Schulz and Conrad, 1996). Conversely, methanogenesis has been shown to predominantly proceed through the hydrogenotrophic route in low-temperature natural (Horn et al., 2003; Kotsyurbenko et al., 2007) and engineered anaerobic bioreactors (McHugh et al.,
2003; Connaughton et al., 2006; Syutsubo et al., 2008). Under low-temperature conditions, improved thermodynamics of methane formation from $\mathrm{H}_{2}$ / $\mathrm{CO}_{2}$, coupled with the enhanced solubility and therefore accessibility of $\mathrm{H}_{2} / \mathrm{CO}_{2}$ in the reactor liquor, are thought to account for this phenomenon (Lettinga et al., 2001). By day 673 of the trial, SMA assays at $15{ }^{\circ} \mathrm{C}$ indicated that maximum potential methanogenesis was channelled through hydrogen 
rather than acetate (Table 2). Indeed, higher hydrogenotrophic methanogenic activity was apparent at $15^{\circ} \mathrm{C}$ than $37^{\circ} \mathrm{C}$. It is possible that operation below sub-optimal temperatures applied a selective pressure favoring the emergence of hydrogenotrophic methanogens. Furthermore, under conditions of low hydrogen availability and sufficiently high biomass concentration, as was likely the case within our system, hydrogenotrophic methanogens have been shown to out-compete homoacetogens for hydrogen (Kotsyurbenko, 2005). The continued detection of psychrophilic $\mathrm{H}_{2}$-utilizing methanogenic activity from our physiological assays further supports this hypothesis (Table 2). By the conclusion of our trial, hydrogenotrophic methanogenic activity remained higher under low-temperature conditions (Table 2), suggesting the enrichment of psychrophilic organisms occurred during long-term cultivation of mesophilic biomass. These data abet Rebac et al. (1999) who posit that psychrophilic homologues are likely to be present in low densities in mesophilic inocula, unable to manifest in activity profiles because of the high numbers of mesophiles. The emergence of putatively psychrophilic acetoclastic activity from cold-acclimatized mesophilic biomass treating glucose-based wastewaters further supports this hypothesis (Akila and Chandra, 2007).

Clone library analysis carried out at the conclusion of the trial indicated that hydrogen-utilizing Methanocorpusculum-like clones had emerged as dominant members of the archaeal community by the conclusion of the trial ( $>50 \%$; Figure 2e). qPCR analysis generally supported clone library, TRFLP and batch physiological data, highlighting the emergence of hydrogenotrophic groups as dominant community members during phase 2. Our Methanocorpusculum-like clones, FJ347529 and FJ347530, were closely associated (sequence homologies, $\geqslant 98 \%$ ) with Methanocorpusculum parvum (accession number, AY260435; Figure 1b), a psychrotolerant hydrogenotrophic isolate from anoxic sediments of polluted pond water (Simankova et al., 2003). These clones likely represent the putative hydrogenotrophic psychrophiles identified by SMA testing. Although found to be able to grow at temperatures $<5{ }^{\circ} \mathrm{C}$, this hydrogen- and formate-utilizing organism was not truly psychrophilic, but merely psychrotolerant, displaying a wide temperature range for growth $\left(5-35{ }^{\circ} \mathrm{C}\right)$, but retaining a mesophilic growth optimum at $25^{\circ} \mathrm{C}$ (Simankova et al., 2003). However, the ability of isolates from cold environments to grow more rapidly at higher temperatures is a poor indication of the ability to adapt to cold environments; activity at low temperatures is the defining characteristic of a cold-adapted consortium (Cavicchioli, 2006). Accordingly, the temperature response observed from our batch activity assays is consistent with a truly psychrophilic methanogenic consortium (Table 2). We will next attempt to isolate these psychrophilic hydrogenotrophic methanogens from the cold-adapted granular biomass.
In summary, multivariate statistical analyses of archaeal and bacterial TRFLP matrices during the start-up phase (day 0-94) illustrated distinct shifts in population dynamics. This observation, coupled with the rapid start-up period ( $>85 \%$ chemical oxygen demand removal after 10 days (McKeown et al., 2009), suggests that the mesophilic sludge adapted quickly to low-temperature operation through changes in the community structure. The microbial population was apparently less dynamic during the latter half of the trial, suggesting that long-term psychrophilic cultivation of mesophilic biomass lead to the selection of a more stable cold-adapted consortium, with a high proportion of both acetoclastic and hydrogenotrophic populations. It seems that a stability threshold was reached, whereby a less dynamic and well-functioning psychroactive consortium was then established. Much work remains to be done to determine the ecophysiology of these groups-particularly of Crenarchaeota, cold-adapted syntrophic bacteria and psychrophilic methanogens-in psychroactive consortia. Research should next focus on novel approaches that explicitly link identity with function, as well as the application of metaproteomic strategies.

\section{Conclusions}

- Low-temperature cultivation of mesophilic inoculum sludge leads to dynamic changes in the microbial community structure;

- Long-term operation under low-temperature conditions can then lead to the selection of a less dynamic cold-adapted methanogenic consortium, including psychrophilic propionate-oxidizing bacteria and hydrogenotrophic methanogens;

- Methanosaeta spp. may be retained within anaerobic granular biofilms during prolonged cold bioreactor operation, allowing high acetoclastic activity and granular stability;

- Hydrogenotrophic Methanomicrobiales can become important members of the methanogenic community at temperature $<10{ }^{\circ} \mathrm{C}$;

- The development of a well-functioning, psychroactive consortium underpinned the high conversion rates and operational stability achieved in the bioreactor.

\section{Acknowledgements}

The financial support of Science Foundation Ireland (SFI Investigator Programme), Irish Research Council for Science Engineering and Technology (IRCSET; Embark Initiative) and a Research Scholarship to CS from Laois County Council are gratefully acknowledged. Standard plasmids for qPCR analysis were kindly provided by Prof. Hwang (POSTECH, Korea). We thank Dr Looman for TRF size analysis (Gene Analysis Service, Berlin, Germany). Inoculum sludge was kindly donated by Pat McCarthy (Carbery Ltd., Ireland). Valuable scientific discussion with Joseph O'Reilly, Padhraig Madden and Carol Morris are appreciatively acknowledged. 


\section{References}

Akila G, Chandra TS. (2007). Performance of an UASB reactor treating synthetic wastewater at low-temperature using cold-adapted seed slurry. Process Biochem 42: 466-471.

Ariesyady HD, Ito T, Yoshiguchi K, Okabe S. (2007). Phylogenetic and functional diversity of propionateoxidizing bacteria in an anaerobic digester sludge. Appl Microbiol Biotechnol 75: 673-683.

Bergamo CM, Di Monaco R, Ratusznei SM, Rodrigues JAD, Zaiat M, Foresti E. (2009). Effects of temperature at different organic loading levels on the performance of a fluidized-bed anaerobic sequencing batch bioreactor. Chem Eng Process 48: 789-796.

Cavicchioli R. (2006). Cold-adapted archaea. Nat Rev Microbiol 4: 331-343.

Chin KJ, Lukow T, Conrad R. (1999). Effect of temperature on structure and function of the methanogenic archaeal community in an anoxic rice field soil. Appl Environ Microbiol 65: 2341-2349.

Chouari R, Le Paslier D, Daegelen P, Ginestet P, Weissenbach J, Sghir A. (2005). Novel predominant archaeal and bacterial groups revealed by molecular analysis of an anaerobic sludge digester. Environ Microbiol 7: 1104-1115.

Coates JD, Coughlan MF, Colleran E. (1996). Simple method for the measurement of the hydrogenotrophic methanogenic activity of anaerobic sludges. J Microbiol Methods 26: 237-246.

Colleran E, Concannon F, Golden T, Geoghegan F, Crumlish B, Killilea $\mathrm{E}$ et al. (1992). Use of methanogenic activity tests to characterise anaerobic sludges, screen for anaerobic biodegradability and determine toxicity thresholds against individual anaerobic trophic groups and species. Water Sci Technol 25: 31-40.

Collins G, McHugh S, Connaughton S, Enright AM, Kearney A, Scully C et al. (2006). New low-temperature applications of anaerobic wastewater treatment. J Environ Sci Health A Toxic/Hazard Subst Environ Eng 41: 881-895.

Collins G, O’Connor L, Mahony T, Gieseke A, de Beer D, O’Flaherty V. (2005). Distribution, localization, and phylogeny of abundant populations of Crenarchaeota in anaerobic granular sludge. Appl Environ Microbiol 71: 7523-7527.

Collins G, Woods A, McHugh S, Carton MW, O’Flaherty V. (2003). Microbial community structure and methanogenic activity during start-up of psychrophilic anaerobic digesters treating synthetic industrial wastewaters. FEMS Microbiol Ecol 46: 159-170.

Connaughton S, Collins G, O’Flaherty V. (2006). Development of microbial community structure and activity in a high-rate anaerobic bioreactor at $18{ }^{\circ} \mathrm{C}$. Water Res 40: 1009-1017.

Conrad R, Bak F, Seitz HJ, Thebrath B, Mayer HP, Schutz H. (1989). Hydrogen turnover by psychrotrophic homoacetogenic and mesophilic methanogenic bacteria in anoxic paddy soil and lake sediment. FEMS Microbiol Ecol 62: 285-294.

Conrad R. (1999). Contribution of hydrogen to methane production and control of hydrogen concentrations in methanogenic soils and sediments. FEMS Microbiol Ecol 28: 193-202.

DeBok FAM, Plugge CM, Stams AJM. (2004). Interspecies electron transfer in methanogenic propionate degrading consortia. Water Res 38: 1368-1375.
DeLong EF. (1992). Archaea in coastal marine environments. Proc Natl Acad Sci USA 89: 5685-5689.

Enright A-M, Collins G, O’Flaherty V. (2007). Temporal microbial diversity changes in solvent-degrading anaerobic granular sludge from low-temperature $\left(15^{\circ} \mathrm{C}\right)$ wastewater treatment bioreactors. Syst Appl Microbiol 30: 471-482.

Enright A-M, McHugh S, Collins G, O’Flaherty V. (2005). Low-temperature anaerobic biological treatment of solvent-containing pharmaceutical wastewater. Water Res 39: 4587-4596.

Fey A, Claus P, Conrad R. (2004). Temporal change of ${ }^{13} \mathrm{C}-$ isotope signatures and methanogenic pathways in rice field soil incubated anoxically at different temperatures. Geochim Cosmochim Acta 68: 293-306.

Galand PE, Fritze H, Yrjala K. (2003). Microsite-dependent changes in methanogenic populations in a boreal oligotrophic fen. Environ Microbiol 5: 1133-1143.

Glissmann K, Chin KJ, Casper P, Conrad R. (2004). Methanogenic pathway and archaeal community structure in the sediment of eutrophic Lake Dagow: effect of temperature. Microb Ecol 48: 389-399.

Griffin ME, McMahon KD, Mackie RI, Raskin L. (1998). Methanogenic population dynamics during start-up of anaerobic digesters treating municipal solid waste and biosolids. Biotechnol Bioeng 57: 342-355.

Griffiths RI, Whiteley AS, O’Donnell AG, Bailey MJ. (2000). Rapid method for coextraction of DNA and RNA from natural environments for analysis of ribosomal DNAand rRNA-based microbial community composition. Appl Environ Microbiol 66: 5488-5491.

Hernon F, Forbes C, Colleran E. (2006). Identification of mesophilic and thermophilic fermentative species in anaerobic granular sludge. Water Sci Technol 54: 1924.

Høj L, Olsen RA, Torsvik VL. (2008). Effects of temperature on the diversity and community structure of known methanogenic groups and other archaea in high Arctic peat. ISME J 2: 37-48.

Horn MA, Matthies C, Kusel K, Schramm A, Drake HL. (2003). Hydrogenotrophic methanogenesis by moderately acid-tolerant methanogens of a methane-emitting acidic peat. Appl Environ Microbiol 69: 74-83.

Jetten MSM, Stams AJM, Zehnder AJB. (1990). Acetate threshold values and acetate activating enzymes in methanogenic bacteria. FEMS Microbiol Ecol 73: 339-344.

Kotsyurbenko OR. (2005). Trophic interactions in the methanogenic microbial community of low-temperature terrestrial ecosystems. FEMS Microbiol Ecol 53: 3-13.

Kotsyurbenko OR, Friedrich MW, Simankova MV, Nozhevnikova AN, Golyshin PN, Timmis KN et al. (2007). Shift from acetoclastic to $\mathrm{H}_{2}$-dependent methanogenes is in a West Siberian peat bog at low $\mathrm{pH}$ values and isolation of an acidophilic Methanobactetium strain. Appl Environ Microbiol 73: 2344-2348.

Lane DJ, Pace B, Olsen GJ, Stahl DA, Sogin ML, Pace NR. (1985). Rapid-determination of $16 S$ ribosomal-RNA sequences for phylogenetic analyses. Proc Natl Acad Sci USA 82: 6955-6959.

Lettinga G, Rebac S, Zeeman G. (2001). Challenge of psychrophilic anaerobic wastewater treatment. Trends Biotechnol 19: 363-370.

Levén L, Eriksson ARB, Schnurer A. (2007). Effect of process temperature on bacterial and archaeal communities in two methanogenic bioreactors treating 
organic household waste. FEMS Microbiol Ecol 59: 683-693.

McHugh S, Carton M, Collins G, O’Flaherty V. (2004). Reactor performance and microbial community dynamics during anaerobic biological treatment of wastewaters at $16-37^{\circ} \mathrm{C}$. FEMS Microbiol Ecol 48: 369-378.

McHugh S, Carton M, Mahony T, O’Flaherty V. (2003). Methanogenic population structure in a variety of anaerobic bioreactors. FEMS Microbiol Lett 219: 297-304.

McHugh S, Collins G, Mahony T, O’Flaherty V. (2005). Biofilm reactor technology for low temperature anaerobic waste treatment: microbiology and process characteristics. Water Sci Technol 52: 107-113.

McKeown RM, Scully C, Mahony T, Collins G, O’Flaherty V. (2009). Long-term (1,243 days) low-temperature (4-15 ${ }^{\circ} \mathrm{C}$ ) anaerobic biotreatment of acidified wastewaters: Bioprocess performance and physiological characteristics. Water Res 43: 1611-1620.

McMahon KD, Zheng DD, Stams AJM, Mackie RI, Raskin L. (2004). Microbial population dynamics during startup and overload conditions of anaerobic digesters treating municipal solid waste and sewage sludge. Biotechnol Bioeng 87: 823-834.

Metje M, Frenzel P. (2007). Methanogenesis and methanogenic pathways in a peat from subarctic permafrost. Environ Microbiol 9: 954-964.

Rebac S, VanLier JB, Lens P, Stams AJM, Dekkers F, Swinkels KTM et al. (1999). Psychrophilic anaerobic treatment of low strength wastewaters. Water Sci Technol 39: 203-210.
Saitou N, Nei M. (1987). The neighbour-joining methoda new method for reconstructing phylogenetic trees. Mol Biol Evol 4: 406-425.

Schulz S, Conrad R. (1996). Influence of temperature on pathways to methane production in the permanently cold profundal sediment of Lake Constance. FEMS Microbiol Ecol 20: 1-14.

Schulz S, Matsuyama H, Conrad R. (1997). Temperature dependence of methane production from different precursors in a profundal sediment (Lake Constance). FEMS Microbiol Ecol 22: 207-213.

Simankova MV, Kotsyurbenko OR, Lueders T, Nozhevnikova AN, Wagner B, Conrad R et al. (2003). Isolation and characterization of new strains of methanogens from cold terrestrial habitats. Syst Appl Microbiol 26: $312-318$.

Stackebrandt E, Goodfellow M. (1991). Nucleic Acid Techniques in Bacterial Systematics. Wiley: England. pp 115-175.

Syutsubo K, Yoochatchaval W, Yoshida H, Nishiyama K, Okawara M, Sumino H et al. (2008). Changes of microbial characteristics of retained sludge during low-temperature operation of an EGSB reactor for lowstrength wastewater treatment. Water Sci Technol 57: 277-281.

Yu Y, Lee C, Kim J, Hwang S. (2005). Groupspecific primer and probe sets to detect methanogenic communities using quantitative real-time polymerase chain reaction. Biotechnol Bioeng 89: 670-679.

Supplementary Information accompanies the paper on The ISME Journal website (http://www.nature.com/ismej) 